\title{
A case report of serpentine-like syndrome and review of literature
}

\author{
Shijing Song ${ }^{1,2}$, Jingjing Wang ${ }^{1,2}$, Jijing Han ${ }^{1,2}$, Yinghua Xuan ${ }^{1,2}$, Wenxue Zhi ${ }^{1,2}$ and Qingqing $W^{1,2^{*}}$ (D)
}

\begin{abstract}
Background: Serpentine-like syndrome (SLS) is a rare foetal abnormality, characterized by brachioesophagus, secondary intrathoracic stomach and vertebral deformity. Herein, we report a case of SLS diagnosed based on imaging, genetic examination and autopsy findings.

Case presentation: From the 19th to 23rd weeks of gestation, the foetus presented with brachioesophagus, secondary intrathoracic stomach, intrathoracic spleen with poly-spleen malformation, spinal deformity and diaphragm dysplasia, and some abdominal organs were partly located in the thoracic cavity. After extensive counselling, the couple opted to terminate the pregnancy. Whole genome sequencing and autopsy were performed. Then, the foetus was diagnosed with SLS.
\end{abstract}

Discussion and conclusions: SLS is characterized by multiorgan deformities and is associated with poor prognosis. Multiorgan deformities can be detected on prenatal sonography using three-dimensional ultrasound technology.

Keywords: Serpentine-like syndrome, Intrathoracic stomach, Brachioesophagus, Vertebral deformity, Case report

\section{Background}

Serpentine-like syndrome (SLS) is a rare abnormality characterized by brachioesophagus, secondary intrathoracic stomach and vertebral anomalies, which are similar to the anatomical structures of snakes. To date, there are only nine reported cases of SLS, and most patients had a poor prognosis. Michael S. Katz et al. first discussed SLS in 2008 [1]. Obstetricians and neonatal paediatricians do not have sufficient knowledge about its characteristics. Hence, the actual number of SLS cases may be higher than that reported. In 2008, another case of SLS was described, and it was characterized by a congenital intrathoracic stomach, short oesophagus, hemivertebrae at the $\mathrm{T} 5$ level and complete gastric outlet obstruction [2].

\footnotetext{
*Correspondence: qingqingwu@ccmu.edu.cn

${ }^{1}$ Ultrasound Department, Beijing Obstetrics and Gynecology Hospital, Capital Medical University, No.251 Yaojiayuan Road, Chaoyang district, Beijing 100026, P. R. China

Full list of author information is available at the end of the article
}

Multiorgan abnormalities can be diagnosed prenatally via ultrasonography (US) and magnetic resonance imaging (MRI). US is advantageous as it is radiationfree and less time-consuming. Thus, it is considered an optimal examination method. However, due to the low spatial resolution of two-dimensional (2D) US, the whole lesion cannot be completely visualized. In addition, in SLS, some abnormalities cannot be directly diagnosed on 2D-US [3]. Advancements in three-dimensional (3D) US can provide opportunities for detecting multiorgan malformations. Hence, an accurate diagnosis, which is essential for adequate counselling and pregnancy management, can be obtained. Crystal Vue (Samsung Medison Co., Ltd., Seoul, South Korea) can improve the spatial resolution of ultrasonic images and can identify the important details of diseases. Hence, it can have a better diagnostic value in detecting multiple organ malformations [4]. 


\section{Case presentation}

Herein, we present a 34-year-old pregnant woman. The patient initially conceived via artificial insemination. However, her pregnancy was subsequently terminated. Next, she had her second artificial insemination and eventually got pregnant. During the first trimester of pregnancy, a nuchal translucency (NT) measuring $1.8 \mathrm{~mm}$ was detected. Moreover, the ductus venous was absent, and a cystic mass was detected in the thoracic cavity. The pregnant woman decided to continue with the pregnancy. Routine foetal ultrasonography and reexamination were performed at 16 and 17 weeks of gestation in another hospital, and the diagnoses differed ((the cystic structure in thoracic cavity VS congenital diaphragmatic hernia (CDH)). At 19 week gestation, 2D-US was conducted at our centre, and the following results were obtained (Fig. 1):

- A cystic structure was observed from the pharynx to the diaphragm in the right thoracic cavity. However, there was no gastric bubble in the abdominal cavity.

- No ductus venous was found. The hepatic portal vein passed behind the intrathoracic stomach and entered the right atrium.

- The probability of oesophagobronchial fistula was not ruled out.
MRI was performed at 21-week gestation, and the following results were obtained (Fig. 1):

- A large cystic structure was noted in the right thoracic cavity of the foetus. However, there were no presence of an intra-abdominal stomach and no filling in the intestine. The diaphragm, which is in the lower posterior part of the heart, was not evident, thereby indicating the existence of diaphragmatic hernia.

- There might be a probability of oesophageal atresia with oesophagobronchial fistula.

- Right lung dysplasia with a small volume of right pleural effusion was observed.

- The continuity of the foetal cervical vertebral body and the anterior edge of the spinal canal might be interrupted, indicating the probability of rachischisis. The anterior edge of the foetal cervical vertebrae might be closely connected with the cystic structure.

Three-dimensional US images were obtained at 23-week gestation and were post-processed with Crystal Vue. The following results were obtained:

- The defect in the middle and posterior diaphragm and some abdominal organs partly entered the chest cavity (Fig. 2).

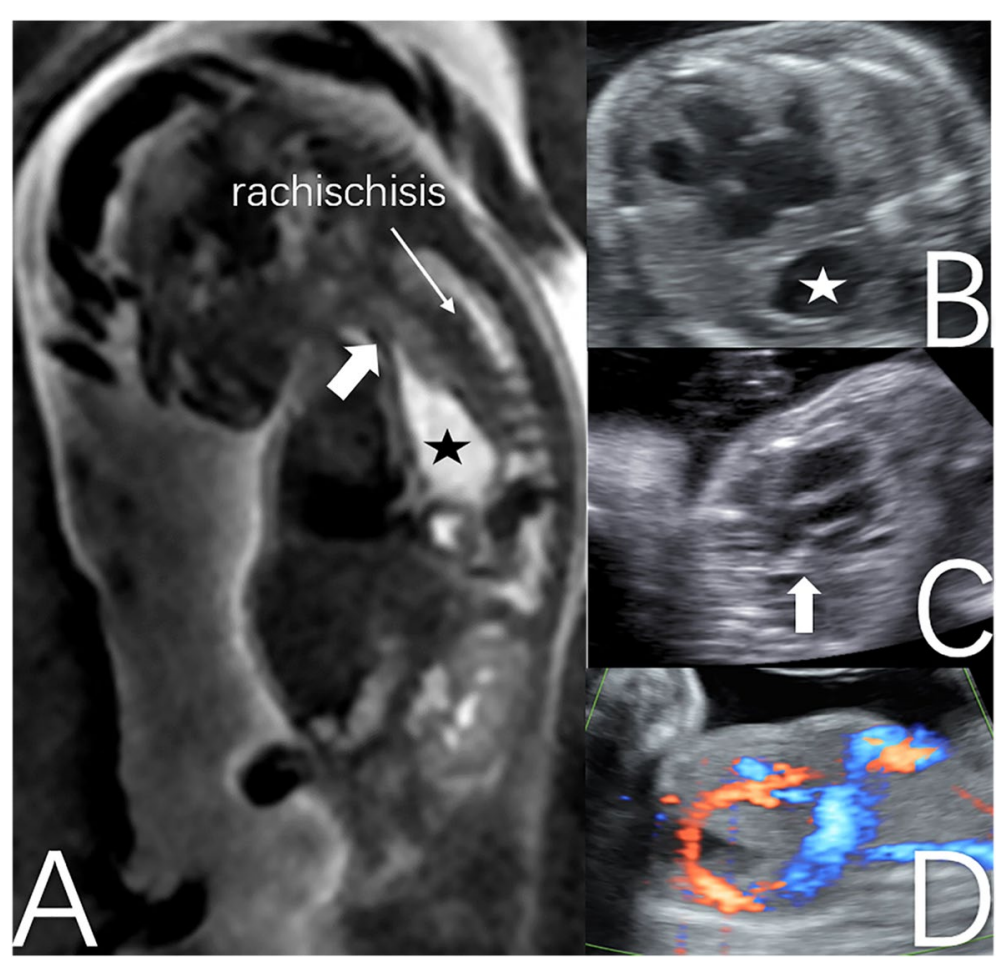

Fig. 1 The MR imaging of short oesophagus, intrathoracic stomach, and rachischisis (A). The intrathoracic stomach behind the heart (B). The oesophagus located at the upper edge of the heart (C). Hepatic portal vein passed behind intrathoracic stomach and entered the right atrial (D). (Asteroids refer to stomach, thick arrows refer to oesophagus) 


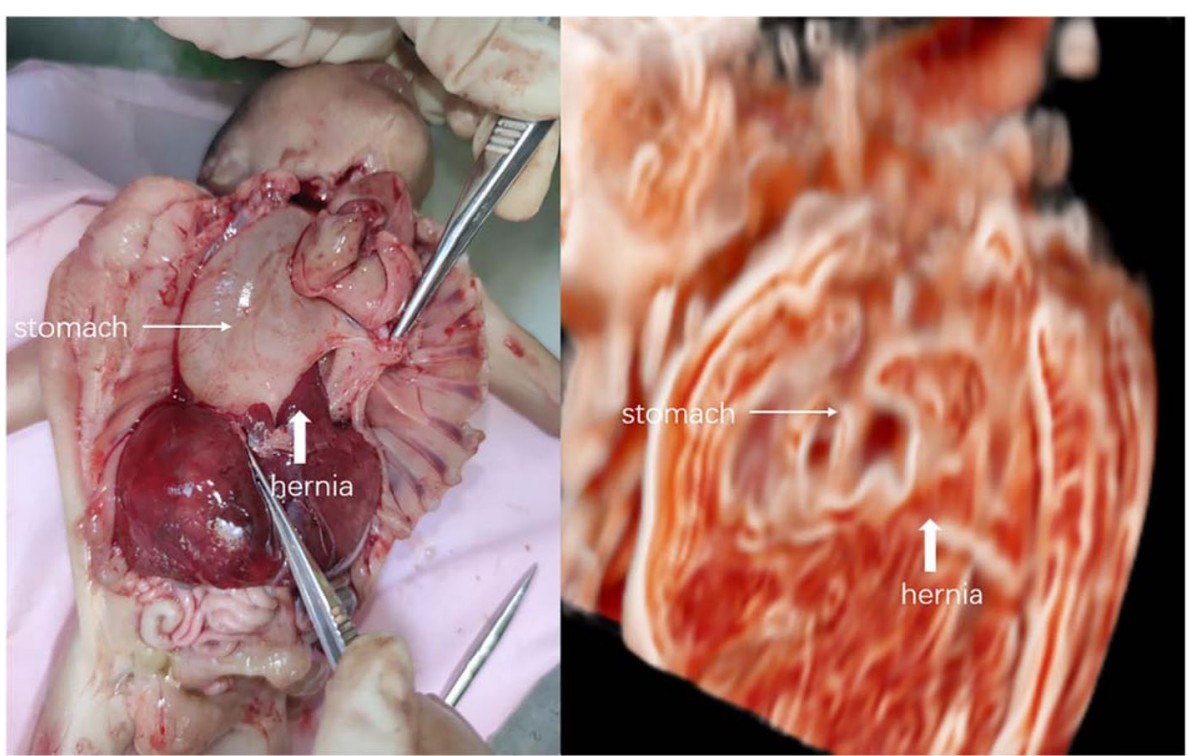

Fig. 2 Abdominal organs enter the thoracic cavity, and nearby intrathoracic stomach

- The oesophagus was short, with a length of $1.5 \mathrm{~cm}$. The end of the oesophagus was connected to the cystic structure, which confirmed the existence of an intrathoracic stomach (Fig. 3).

The patient terminated the pregnancy, and an autopsy was then performed with the patient's consent. The autopsy results were as follows:
- The foetus weighed $650 \mathrm{~g}$, and its length was $34 \mathrm{~cm}$. Moreover, short neck and abdominal retraction were noted.

- The cervical vertebra was bent to the left, and the foetal head was inclined to the right shoulder. Vertebral dysplasia was observed at the C2-C6 levels with $\mathrm{C} 2-\mathrm{C} 4$ vertebral body fusion and disorganization, and there was an anterior fissure at the C5-C6 levels with the defect size was $0.4 \times 0.3 \mathrm{~cm}$. However,

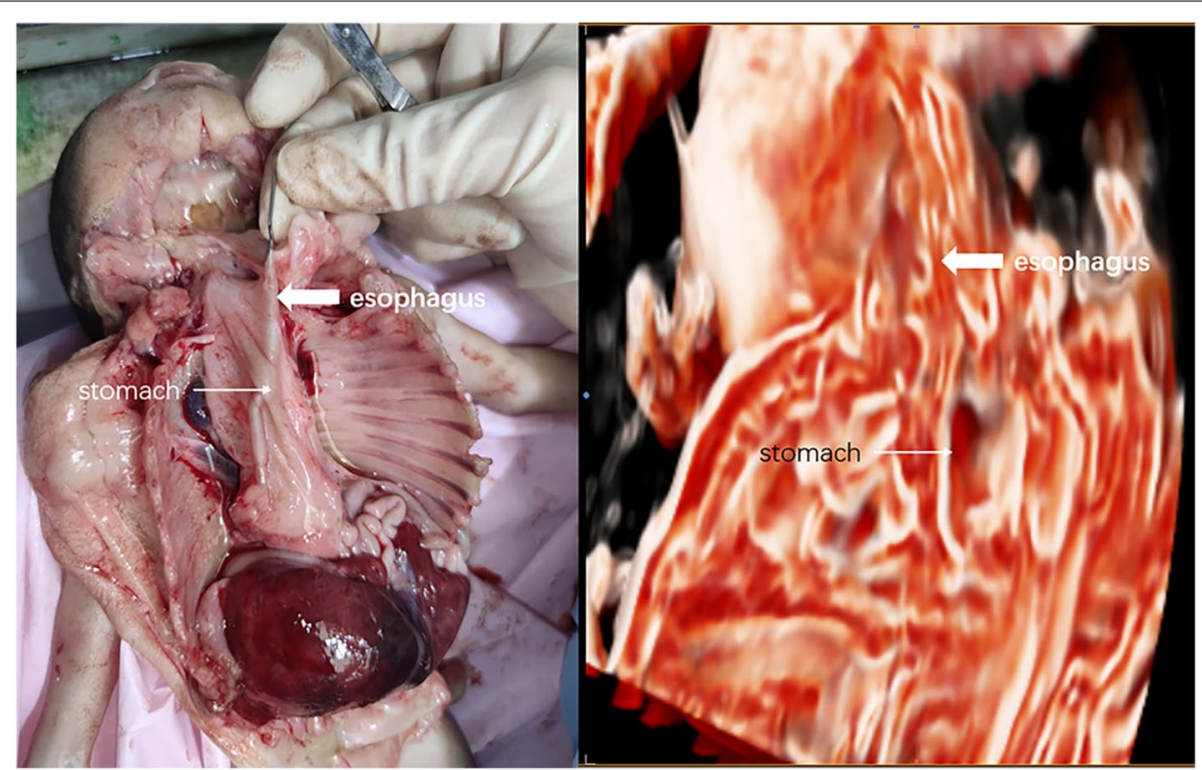

Fig. 3 The foetal oesophagus connected with intrathoracic stomach 
the spinal cord tissue was normal. The defect in the cervical spine was closely connected to the serosa of the transitional area of the oesophagus and cardia.

- The cardia was fixed at the site of cervical spondylolysis in front of the C6 level. The whole stomach was in the right thoracic cavity with a reversed rotation, thereby suggesting a lesser curvature on the left and a greater curvature on the right. After pushing the stomach, a clear yellow liquid flowed out from the nasal cavity.

- On microscopy, the smooth muscle of the stomach was connected to the cartilage.

- The oesophagus was short, with a length of $1.5 \mathrm{~cm}$.

- The duodenum presented with atresia. However, there was no meconium in the intestine.

- There was a defect in the diaphragm at the dorsal side. Parts of the duodenum, pancreas, left and caudate lobes of the liver and whole spleen were in the right chest. The spleen (with poly-spleen malformation) was behind the stomach.

- The mediastinum and the heart were at the left thoracic cavity.

- Right lung dysplasia with bilobate deformity was observed. The superior lobe of the right lung was located at the middle of the chest in front of the mediastinum, and the lower lobe at the right chest.

- The superior vena cava flowed into the right atrium above the interlobular fissure. The main trunk of the hepatic portal vein was pulled into the thoracic cavity and directly flowed into the superior vena cava. No innominate vein was found. The left superior vena cava persistently flowed into the right atrium (Fig. 4).

The foetus was diagnosed with SLS due to the coexistence of brachioesophagus, secondary intrathoracic stomach and vertebral anomalies. Chorionic villus samples were obtained at 13 weeks of gestation. G-banded karyotype analysis was performed, and results did not reveal chromosomal abnormalities. Simultaneously, array comparative genomic hybridization and polymerase chain reaction Gene Scan did not show gene copy number variations. The whole genome sequence of humans was provided using the high-throughput sequencing technology. No pathogenic variants were identified. The likely pathogenic variants were found in MKS transition zone complex subunit 1 (MKS1, chr17:56284466, NM_017777.3: C.1387C > T) and docking protein 7 (DOK7, chr4:3494599, NM_173660.4: C.886C > T). Variants of uncertain significance were detected in microtubule actin crosslinking factor 1 (MACF1, chr1:39888093, NM_012090.4: c.9678G >C), beta 3-glucosyltransferase (B3GLCT, chr13:31789179, NM_194318.3: c.71-9T >C) and RAB3 GTPase activating non-catalytic protein subunit 2 (RAB3GAP2, chr1:220325081, NM_012414.3: c.3893A > C). Two genetic specialists were consulted, and they confirmed that such variants were not associated with the clinical phenotype.

\section{Discussion and conclusions}

Snakes have an intrathoracic stomach and rachischisis-like spinal vertebrae. In 2008, Michael S. Katz et al. defined SLS as a condition characterized by foetal malformations such as short oesophagus, intrathoracic stomach and vertebral rachischisis. Moreover, in the same year, Alex W.K. Leung et al. reported a foetus presenting with the characteristics of SLS including thoracic hemivertebrae at the T5 level, short oesophagus and intrathoracic stomach. The current study assessed case reports about SLS in the English literature. In total, nine cases were included in our review, and the current case is the 10th.

Table 1 shows the general information about pregnant women and their foetuses. There were two primiparas and five multiparas. Three articles did not include information about the history of pregnancy and childbirth. All multipara women $(n=5)$ had a history of adverse pregnancy. Of 10 foetuses, 5 were male and 5 female. Of

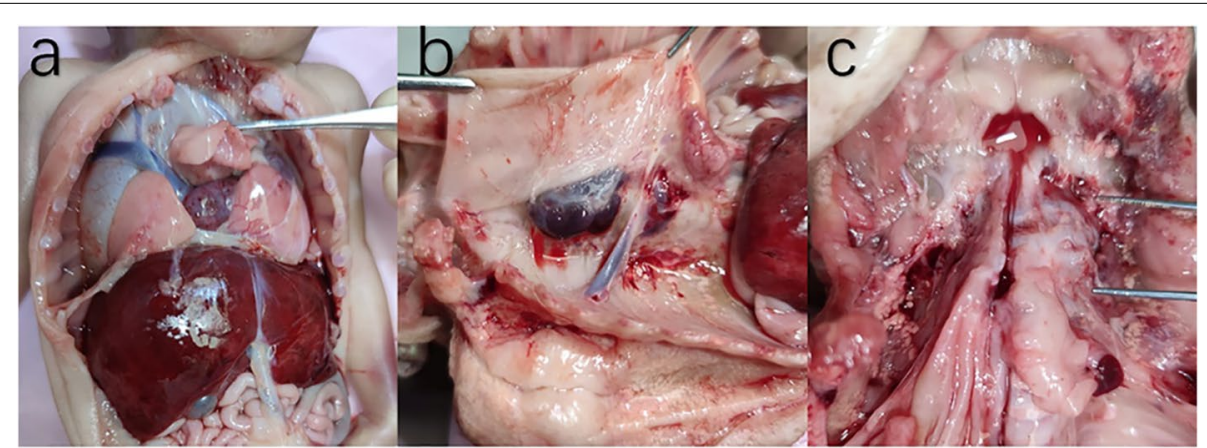

Fig. 4 The multiple organs deformations: right lung presented as two lobes, abnormal position of superior vena cava, hepatomegaly (a); poly-spleen behind intrathoracic stomach (b); hemivertebra and rachischisis (c) 
Table 1 General data of pregnant women and foetuses

\begin{tabular}{|c|c|c|c|c|c|}
\hline Case & Maternal age & History of gestation & Previous diagnosis & Foetal gender & Outcome \\
\hline $\begin{array}{l}\text { case } 1 \\
{[2]}\end{array}$ & 28 & none & $\begin{array}{l}\text { hiatal hernia\pulmonary sequestration } \backslash \\
\text { diaphragmatic hernia }\end{array}$ & $46, X X$ & death after operation \\
\hline $\begin{array}{l}\text { case } 2 \\
{[1]}\end{array}$ & 40 & G1P0\artificial insemination & $\begin{array}{l}\text { polyhydramnios and an absent gastric } \\
\text { bubble }\end{array}$ & $46, X X$ & alive after operation \\
\hline $\begin{array}{l}\text { case } 3 \\
{[1]}\end{array}$ & 18 & none & $\begin{array}{l}\text { diaphragmatic hernia \possible transposi- } \\
\text { tion of the great vessels }\end{array}$ & $46, X X$ & death without operation \\
\hline $\begin{array}{l}\text { case } 4 \\
{[5]}\end{array}$ & 44 & G3P0 & $\begin{array}{l}\text { median diaphragmatic hernia with intratho- } \\
\text { racic stomach }\end{array}$ & $46, X Y$ & death after operation \\
\hline $\begin{array}{l}\text { case } 5 \\
{[6]}\end{array}$ & 28 & none & congenital diaphragmatic hernia & $46, X Y$ & death after operation \\
\hline $\begin{array}{l}\text { case } 6 \\
{[7]}\end{array}$ & 37 & G1P0 & congenital diaphragmatic hernia & $46, X Y$ & death without operation \\
\hline $\begin{array}{l}\text { case } 7 \\
{[8]}\end{array}$ & 27 & G2P0 & $\begin{array}{l}\text { encephalocele, cystic hygroma and polyhy- } \\
\text { dramnios }\end{array}$ & $46, X X$ & alive after operation \\
\hline $\begin{array}{l}\text { case } 8 \\
{[9]}\end{array}$ & none & G2P0 & midline diaphragmatic hernia & $46, X X$ & death without operation \\
\hline $\begin{array}{l}\text { case } 9 \\
{[3]}\end{array}$ & 35 & G3P0 & congenital diaphragmatic hernia & $46, X Y$ & termination of pregnancy, died \\
\hline our case & 34 & G2P0 & $\begin{array}{l}\text { congenital diaphragmatic hernia\ Cystic } \\
\text { structure of thoracic cavity } \backslash \text { esophago- } \\
\text { tracheal fistula }\end{array}$ & $46, X Y$ & termination of pregnancy, Died \\
\hline
\end{tabular}

Table 2 Multiple organs malformation information

\begin{tabular}{|c|c|c|c|c|c|c|}
\hline Case & $\begin{array}{l}\text { Short } \\
\text { oesophagus }\end{array}$ & $\begin{array}{l}\text { Intrathoracic } \\
\text { stomach }\end{array}$ & Spinal deformity & Deformity of other organs & $\begin{array}{l}\text { Intrathoracic abdominal } \\
\text { organs }\end{array}$ & Karyotype \\
\hline $\begin{array}{l}\text { case } 1 \\
{[2]}\end{array}$ & yes & yes & T5 hemivertebra & stomach outlet & part of intestine & normal \\
\hline $\begin{array}{l}\text { case } 2 \\
{[1]}\end{array}$ & yes & yes & cervical spondylolysis (C1-C4) & $\begin{array}{l}\text { right ulna and radius } \backslash \text { stom- } \\
\text { ach outlet } \backslash \text { spleen }\end{array}$ & spleen & normal \\
\hline $\begin{array}{l}\text { case } 3 \\
{[1]}\end{array}$ & yes & yes & $\begin{array}{l}\text { cervical spondylolysis (C2-C5); } \\
\text { small T5 vertebral body }\end{array}$ & $\begin{array}{l}\text { right foot } \backslash \text { spleen } \backslash \text { superior } \\
\text { vena cava } \backslash \text { heart } \backslash \text { ductus arte- } \\
\text { riosus } \backslash \text { pulmonary venous } \backslash \\
\text { gut }\end{array}$ & none & normal \\
\hline $\begin{array}{l}\text { case } 4 \\
{[5]}\end{array}$ & yes & yes & cervical scoliosis and fusion & $\begin{array}{l}\text { right lung } \backslash \text { umbilical artery } \\
\text { ductus venosus } \backslash \text { cardiomeg- } \\
\text { aly \Intestinal\liver } \backslash \text { gallblad- } \\
\text { der } \backslash \text { colon\ fingers }\end{array}$ & $\begin{array}{l}\text { duodenum } \backslash \text { head of pan- } \\
\text { creas } \backslash \text { spleen } \backslash \text { first jejunal } \\
\text { loop }\end{array}$ & normal \\
\hline $\begin{array}{l}\text { case } 5 \\
{[6]}\end{array}$ & yes & yes & cervical spondylolysis & duodenal & duodenum \pancreas \spleen & normal \\
\hline $\begin{array}{l}\text { case } 6 \\
{[7]}\end{array}$ & yes & yes & $\begin{array}{l}\text { cervical hypoplastic and } \\
\text { rachischisis and partly fused } \\
\text { and disorganization }\end{array}$ & $\begin{array}{l}\text { duodenum } \backslash \text { spleen } \backslash \text { gallblad- } \\
\text { der } \backslash \text { pancreas }\end{array}$ & none & normal \\
\hline $\begin{array}{l}\text { case } 7 \\
{[8]}\end{array}$ & yes & yes & split notochord malformation & $\begin{array}{l}\text { encephalocele, midline local- } \\
\text { ized liver }\end{array}$ & none & unknown \\
\hline $\begin{array}{l}\text { case } 8 \\
{[9]}\end{array}$ & yes & yes & $\begin{array}{l}\text { large fissure from cervical to } \\
\text { thoracic vertebra }\end{array}$ & $\begin{array}{l}F G R \backslash \text { ears } \backslash \text { lip } \backslash \text { palmar creases } \backslash \\
\text { bladder } \backslash \text { heart } \backslash \text { superior vena } \\
\text { cava } \backslash \text { lung } \backslash \text { cystic canal }\end{array}$ & spleen, part of pancreas & normal \\
\hline $\begin{array}{l}\text { case } 9 \\
\text { [3] }\end{array}$ & yes & yes & $\begin{array}{l}\text { severe case of rachischisis } \\
\text { from lower cervical to upper } \\
\text { thoracic vertebrae }\end{array}$ & heart position\lungs & $\begin{array}{l}\text { spleen, pancreas, part of } \\
\text { duodenum }\end{array}$ & normal \\
\hline our case & yes & yes & $\begin{array}{l}\text { C2-C6 dysplasia; C2-C4 fusion } \\
\text { and disorganization; anterior } \\
\text { fissure of } \mathrm{C} 5-\mathrm{C} 6\end{array}$ & $\begin{array}{l}\text { right lung } \backslash \text { spleen } \backslash \text { duodenal } \backslash \\
\text { persistent left superior vena } \\
\text { cava }\end{array}$ & $\begin{array}{l}\text { part of duodenum, pancreas, } \\
\text { part of liver, spleen }\end{array}$ & normal \\
\hline
\end{tabular}


five foetuses who underwent surgery, three (60\%) died, and two (40\%) survived with the help of assistive devices. Moreover, three foetuses died without surgery. In two cases, the pregnancy was terminated. Eight patients were misdiagnosed with $\mathrm{CDH}$ and one with pulmonary sequestration. Further, one patient was diagnosed with polyhydramnios and an absent gastric bubble.

Table 2 shows data about concomitant deformities. All patients presented with brachioesophagus, intrathoracic stomach and spinal deformity. Nine foetuses had normal karyotypes. However, the genetic results of one patient were unknown. Eight $(80 \%)$ patients presented with deformities in the intestine, seven (70\%) in the spleen, four $(40 \%)$ in the lungs, four $(40 \%)$ in the great vessel, three $(30 \%)$ in the heart, three $(30 \%)$ in the limbs, three $(30 \%)$ in the liver, three $(30 \%)$ in the gallbladder and cystic canal, two (20\%) in the stomach outlet and two (20\%) in the central nervous system.

The prognosis of SLS is poor, and the survival rate after surgery is $40 \%$. The outcome of the surviving foetuses is poor. Fetoscopic endotracheal occlusion (FETO) can improve the survival rate of foetuses with $\mathrm{CDH}$ [10]. Leftsided diaphragmatic hernia is the most common type of $\mathrm{CDH}$, and it may lead to intrathoracic stomach and pulmonary hypoplasia, which is similar to SLS. Intrathoracic stomach compression can impair the development of foetal lungs. FETO might improve the survival of foetuses with SLS. However, compared with $\mathrm{CDH}$, FETO might be less beneficial in the foetus of our report. In $\mathrm{CDH}$, the abdominal organs that herniated into the thoracic cavity are not fixed. Resistance from the hernia sac in $\mathrm{CDH}$ is lesser than that from the fixed intrathoracic stomach in our case. No genetic variant associated with the clinical phenotype was detected via G-banded karyotype analysis, array comparative genomic hybridization, polymerase chain reaction Gene Scan and the whole genome sequence of humans. The cause of SLS remains unclear. All multipara women $(n=5)$ had a history of adverse pregnancy. Hence, this factor can be correlated with SLS. In 8 of 10 cases, spinal deformities occurred in the cervicothoracic segment. This phenomenon might be attributed to unknown factors affecting the differentiation of the cervical vertebral body and oesophageal development. Hence, as there is no adhesion and fistula between the oesophagus and trachea, this condition may occur during the embryonic stage, which is after the foregut differentiates into the trachea and oesophagus and before the oesophageal lengthens. A short oesophagus may cause diaphragmatic dysplasia. In the embryonic stage, the dorsal mesentery of the oesophagus develops into the dorsal and median parts of the diaphragm [11]. Based on the current and previous reports, the oesophageal dorsal mesentery does not play a role in the development of diaphragmatic muscle in SLS, resulting in partial dysplasia in the dorsal and median parts of the diaphragm. In this case, the dorsal mesentery of the oesophagus might have fused with the adjacent visceral pleura. Our hypothesis could be validated by the autopsy results. That is, the serosa at the cardia was fixed in front of the C6 level, and the smooth muscle of the stomach was connected to the cartilage. The bilobar malformation of the right lung could possibly be caused by gastric compression in the chest or by failure in the division and development of the right lung bud during the different phases of lung development [12]. Spleen development starts in the 5th week of gestation, and its location changes with the stomach between the 6th and 7th weeks. Asplenia and polysplenia are rare congenital abnormalities of the spleen, $40-70 \%$ of them combined with other defects [13]. In our case, the foetal stomach and spleen developed in the thoracic cavity. In $\mathrm{CDH}$, the position and morphology of the spleen and stomach were normal during the embryonic stage. Even if the spleen is in the hernia, it has a normal morphology, and its location is not fixed. In SLS, the spleen had an abnormal morphology, and its location is fixed.

\section{Differential diagnosis}

1. The diaphragmatic defect in $\mathrm{CDH}$ differs from that in SLS, except for the presence of oesophageal hiatal hernia. In SLS and oesophageal hiatal hernia, the diaphragmatic defects are in the middle and posterior side of the diaphragm. In other $\mathrm{CDH}$ types, the diaphragmatic defects are in other locations [14].

2. When an intrathoracic stomach is detected, it is mandatory to exclude $\mathrm{CDH}$. In all $\mathrm{CDH}$ types, the abdominal organs that herniated into the thoracic cavity are not fixed. With high thoracic pressure, the herniated organs may partly enter the abdominal cavity [15]. In SLS, the stomach and other organs that should be in the abdominal cavity are fixed in the chest, and the other abdominal organ does not herniate into the thorax.

3. The location and morphology of the spleen in $\mathrm{CDH}$ are commonly normal. However, in SLS, it may be located in the thoracic cavity, and deformities including poly-spleen and no-spleen are observed occasionally.

\section{Differential diagnosis of other thoracic diseases}

1. SLS is characterized by diaphragmatic dysplasia and intrathoracic diseases caused by an integral diaphragm.

2. The blood vessels of the intrathoracic stomach come from the celiac trunk, the blood vessels of pulmonary 
sequestration from the aorta and the blood supply of other thoracic diseases from the thoracic vessels [16].

3. The size and location of the stomach are normal in congenital lung lesions.

The length of the oesophagus, integrity of the diaphragm and location of the stomach are important for obtaining a differential diagnosis in SLS with CDH and other thoracic diseases. Since 2D-US remains the standard tool for morphology scan screening, foetal morphological features assessed via 2D-US should be further addressed in detail. Novel 3D-US rendering technique is effective for identifying the perception of depth while preserving context and surface information [17]. Moreover, it can detect the subtle structures of foetuses such as those of the oesophagus, diaphragm and stomach, and the relationships between different structures. Therefore, it has a greater diagnostic value for multiorgan malformations.

\section{Abbreviations \\ SLS: Serpentine-like syndrome; WGS: Whole genome sequencing; US: Ultrasound; 2D-US: Two-dimension ultrasound; 3D-US: Three--dimension ultrasound; MR: Magnetic resonance; $\mathrm{CDH}$ : Congenital diaphragmatic hernia.}

\section{Acknowledgments}

We thank the patient and her parents for participating in this study.

\section{Authors' contributions}

SJS drafted the manuscript. QQW and JJH and YHX revised the manuscript and contributed to the interpretation of data. YHX and QQW collected 2D-US images. SJS collected and rendered the 3D-US images. WXZ performed autopsy on the foetus. JJW reviewed the relevant literature. All authors read and approved the final manuscript. All authors take full responsibility for manuscript content, accuracy, and integrity.

\section{Funding}

The authors received no financial support for this study.

\section{Availability of data and materials}

Datasets from this study are available upon reasonable request from the corresponding author.

\section{Declarations}

Ethics approval and consent to participate Not applicable.

\section{Consent for publication}

Written informed consent was obtained from the patient for publication of this case report and any accompanying images. A copy of the written consent is available for review by the Editor of this journal.

\section{Competing interests}

The authors declare that they have no competing interests.

\section{Author details}

${ }^{1}$ Ultrasound Department, Beijing Obstetrics and Gynecology Hospital, Capital Medical University, No.251 Yaojiayuan Road, Chaoyang district, Beijing 100026, P. R. China. ${ }^{2}$ Beijing Maternal and Child Health Care Hospital, Beijing, P. R. China.

\section{References}

1. Katz MS, Hess DJ, Caty MG, Khan AR, Glick PL. Of snakes and babies: intrathoracic stomach and vertebral rachischisis. A serpentine-like syndrome? J Pediatr Surg. 2008;43(7):1385-9. https://doi.org/10.1016/j.jpedsurg.2008.02.055.

2. Leung AW, Lam HS, Chu WC, Lee KH, Tam YH, Ng PC. Congenital intrathoracic stomach: short esophagus or hiatal hernia? Neonatology. 2008;93(3):178-81. https://doi.org/10.1159/000108927.

3. Mimura K, Endo M, Matsuoka K, Tomimatsu T, Tazuke Y, Okuyama H, et al. Prenatal findings of serpentine-like syndrome with congenital intrathoracic stomach: differential diagnosis from congenital diaphragmatic hernia. J Med Ultrason (2001). 2019;46(2):263-6. https://doi.org/10.1007/ s10396-018-0896-8.

4. Ddall'asta A, Grisolia G, Nanni M, Volpe N, Schera GBL, Frusca T, et al. Sonographic demonstration of fetal esophagus using three-dimensional ultrasound imaging. Ultrasound Obstet Gynecol. 2019;54(6):746-51. https:// doi.org/10.1002/uog.20221.

5. Deprez FC, Debauche C, Clapuyt P, de Goyet JD. Multiorgan developmental anomalies presenting as a variation of the serpentine-like syndrome: cervical fusion and brachioesophagus with intrathoracic stomach and malposition of duodenopancreas and spleen. J Pediatr Surg. 2009;44(8):E25-8. https://doi.org/10.1016/j.jpedsurg.2009.05.024.

6. Nakamura H, Okazaki T, Koga H, Lane GJ, Yamataka A. Congenital brachioesophagus with secondary intrathoracic stomach associated with rachischisis described as "serpentine-like syndrome": a case report and literature review. Pediatr Surg Int. 2012;28(1):63-6. https://doi.org/10.1007/ s00383-011-3000-7.

7. Dargan D, Mcmorrow A, Bourke TW, Mccallion WA, Verner AM, Lyons J, et al. Extensive cervical spine and foregut anomaly in 'serpentine syndrome.' Int J Surg Case Rep. 2013;4(5):511-4. https://doi.org/10.1016/j.jijscr.2012.11.005.

8. Dorum BA, Korkmaz S, Ozkan H, Koksal N, Bagci O, Yazici Z, et al. Serpentine-like syndrome associated with encephalocele. Clin Dysmorphol. 2016;25(3):110-2. https://doi.org/10.1097/MCD.0000000000000122.

9. Beleza-Meireles A, Steenhaut P, Hocq C, Clapuyt P, Bernard P, Debauche $C$, et al. "serpentine-like syndrome"-a very rare multiple malformation syndrome characterised by brachioesophagus and vertebral anomalies. Eur J Med Genet. 2017;60(2):100-4. https://doi.org/10.1016/j.ejmg.2016.11.002.

10. Chatterjee D, Ing RJ, Gien J. Update on congenital diaphragmatic hernia. Anesth Analg. 2020;131(3):808-21. https://doi.org/10.1213/ANE.00000 00000004324.

11. Kaufmann P. The Anatomical Basis of Mouse Development. By MATTHEW H. KAUFMAN and JONATHAN B. L. BARD. (Pp. xii+291; fully illustrated; \$99.95; ISBN 012402060 7.) San Diego: Academic Press. 1999. J Anat. 2000;197(2):39-42. https://doi.org/10.1046/j.1469-7580.2000.197203313.x.

12. Cotten CM. Pulmonary hypoplasia. Semin Fetal Neonatal Med. 2017;22(4):250-5. https://doi.org/10.1016/j.siny.2017.06.004.

13. Varga I, Babala J, Kachlik D. Anatomic variations of the spleen: current state of terminology, classification, and embryological background. Surg Radiol Anat. 2018;40(1):21-9. https://doi.org/10.1007/s00276-017-1893-0.

14. Kosiński P, Wielgoś M. Congenital diaphragmatic hernia: pathogenesis, prenatal diagnosis and management - literature review. Ginekol Pol. 2017;88(1):24-30. https://doi.org/10.5603/GP.a2017.0005.

15. Kovler ML, Jelin EB. Fetal intervention for congenital diaphragmatic hernia. Semin Pediatr Surg. 2019;28(4). https://doi.org/10.1053/j.sempedsurg.2019. 07.001.

16. Zobel M, Gologorsky R, Lee H, Vu L. Congenital lung lesions. Semin Pediatr Surg. 2019;28(4):150821. https://doi.org/10.1053/j.sempedsurg.2019.07.004.

17. Shah H, Al-Memar M, De Bakker B, Fourie H, Lees C, Bourne T. The firsttrimester fetal central nervous system: a novel ultrasonographic perspective. Am J Obstet Gynecol. 2017;217(2):220-1. https://doi.org/10.1016/j.ajog. 2017.05.053.

\section{Publisher's Note}

Springer Nature remains neutral with regard to jurisdictional claims in published maps and institutional affiliations. 